\title{
Early leaf removal impact on volatile composition of Tempranillo wines
}

\author{
Mar Vilanova, ${ }^{a *}$ Maria Paz Diago, ${ }^{b}$ Zlatina Genisheva, ${ }^{c}$ José Maria Oliveira ${ }^{c}$ \\ and Javier Tardaguila ${ }^{b}$
}

\begin{abstract}
BACKGROUND: Early defoliation is a very innovative technique in viticulture used for yield management. The effects of early leaf removal performed manually and mechanically at two different phenological stages, pre-bloom and fruit set, on the volatile composition of Tempranillo (Vitis vinifera L.) wines were studied. Volatiles were identified and quantified by gas chromatography.

RESULTS: Early leaf removal only modified the total concentrations of $C_{6}$ compounds and acetates, whereas total alcohols, esters, volatile acids and terpenes remained generally unaffected. Early defoliation induced a significant reduction in $\mathrm{C}_{6}$ compounds and increased the concentrations of acetates in Tempranillo wines. An effect of timing (pre-bloom vs fruit set) alone was observed for all acetates analysed. Regarding the method of defoliation (manual vs mechanical), significant differences in some ethyl ester (ethyl-2-methylbutyrate and ethyl octanoate) and volatile acid concentrations were observed among treatments. Ethyl octanoate, 2-phenylethyl acetate, 3-methylbutyl acetate and hexanoic acid, with OAV (odour activity value) $>1$ and mainly fruity and floral odour descriptors, showed higher levels after early defoliation treatments compared with non-defoliated vines. Principal component analysis illustrated the difference in wines from defoliated and non-defoliated treatments based on their volatile composition.
\end{abstract}

CONCLUSION: It can be concluded that early leaf removal significantly modified the wine aroma compounds, increasing or decreasing several of these compounds.

(c) 2011 Society of Chemical Industry

Keywords: early defoliation; volatile compounds; wine composition; Tempranillo

\section{INTRODUCTION}

In the last decade, new viticulture techniques have been developed around the world for cost-effective yield management with the aim of improving grape and wine quality. Early defoliation is an innovative viticulture practice aimed at regulating yield components and improving grape quality. ${ }^{1,2}$ In previous studies, early defoliation induced smaller and looser clusters that were less susceptible to Botrytis rot. ${ }^{1,3}$ Concentrations of soluble solids, phenols and anthocyanins increased in grapes ${ }^{1,2}$ and wines ${ }^{3}$ from early defoliated vines.

The goal and timing of early defoliation, which is carried out around flowering, are different from those of 'classic' leaf removal, which is performed between fruit set and veraison in different climatic zones and varieties. ${ }^{4-7}$ Classic leaf removal improves light exposure and air circulation around clusters of very dense canopies, but it does not modify yield components..$^{5,8,9}$ The positive impact of early defoliation on grape and wine composition is based upon its effects on leaf/fruit ratio, canopy porosity, fruit (cluster and berry) exposure $\mathrm{e}^{3}$ and skin/berry ratio. ${ }^{10}$ These effects contrast with manual cluster thinning, the most used technique in viticulture for yield control, which does not significantly affect the canopy microclimate. Furthermore, early leaf removal could be applied by a defoliator machine for cost-effective yield control with improved grape $^{2}$ and wine composition ${ }^{3}$ and aroma attributes. ${ }^{11}$
The flavour and aroma compounds in ripe grapes depend on multiple variables, including variety, environmental conditions during the growing season and cultural practices. ${ }^{12}$ In grape berries there are hundreds of compounds that could potentially contribute to the flavour and aroma of wine. Wine is a complex mixture in which flavour and aroma compounds have multiple origins. ${ }^{12}$ Among the compounds responsible for wine aroma are terpenols, $\mathrm{C}_{13}$ norisoprenoids, alcohols, esters, volatile acids and volatile phenols. ${ }^{13-15}$ The volatile composition of grapes has been shown to be affected by leaf removal. ${ }^{16-18}$ In classic leaf removal trials the volatile composition of wines was observed to increase owing to the enhancement of several free and bound compounds that are important components of fruit quality ${ }^{17}$ and have higher muscat and floral/perfume aromas. ${ }^{18}$ Studies carried out in Shiraz wine showed that shaded fruit resulted in decreased concentra-

\footnotetext{
* Correspondence to: Mar Vilanova, Misión Biológica de Galicia (CSIC), POBox 28, E-36080 Pontevedra, Spain.E-mail:mvilanova@mbg.cesga.es

a Misión Biológica de Galicia (CSIC), PO Box 28, E-36080 Pontevedra, Spain

b Instituto de Ciencias de la Vid y del Vino (Universidad de la Rioja, CSIC, Gobierno de La Rioja). Madre de Dios 51, E-26006 Logroño, Spain

C IBB-Institute for Biotechnology and Bioengineering, Centre of Biological Engineering, Universidade do Minho, E-4710-057 Braga, Portugal
} 
tions of $\mathrm{C}_{13}$ norisoprenoids. ${ }^{19}$ Nevertheless, to our knowledge, no information on the effects of early defoliation on the volatile profile and composition of the berries exists in the literature.

In previous research we studied the effects of the timing of manual and mechanical early defoliation on the sensory properties of Tempranillo wines. ${ }^{11}$ A deeper understanding of the impact of yield management and changes in cluster exposure induced by early defoliation on the volatile compounds is required. The aim of the present study, conducted with the same samples from the 2008 vintage of the previous work, ${ }^{11}$ was to identify and quantify the main differences in volatile composition of Tempranillo (Vitis vinifera $\mathrm{L}$.) wines affected by manual and mechanical defoliation at two timings (fruit set and pre-bloom).

\section{MATERIALS AND METHODS}

\section{Viticultural treatments}

This study was conducted in a commercial V. vinifera L. cv. Tempranillo vineyard in La Rioja, Spain during the 2008 season. The experimental design, described in Diago et al., ${ }^{11}$ compared the following treatments: (a) control or non-defoliated; (b) manual removal of the first eight basal leaves at pre-bloom, at stage $19^{20}$ (Man-PB); (c) manual removal of the first eight basal leaves at fruit set, at stage $27^{20}$ (Man-FS); (d) mechanical defoliation at prebloom (Mec-PB); (e) mechanical defoliation at fruit set (Mec-FS). Mechanical leaf removal was conducted with a tractor-mounted pulsed air leaf remover (Collard, Bouzy, France). The treatments were arranged in a completely randomised design that consisted of five replicates of 20-vine plots for each treatment. In each replication plot, five vines were tagged for agronomical and grape quality assessment. On each vine, one representative shoot was also labelled for the estimation of total leaf area.

\section{Cluster exposure and canopy porosity}

Appraisal of canopy porosity and cluster exposure was carried out by digital image analysis using the methodology proposed by Tardaguila et al. ${ }^{3}$ For each treatment the 25 labelled vines were photographed between 07:00 and 09:00 a week before harvest. The digital images were analysed using the image analysis software Envi 4.3 (ITT Visual Information Solutions, Boulder, CO, USA). Red, green and blue threshold values and tolerances were set manually to establish two different hue classes: clusters and canopy porosity. In order to avoid the influence of yield on the percentage of cluster pixels in the image, the ratio pixels of cluster/yield per vine was calculated.

\section{Microscale fermentations}

The grapes from five labelled vines per replicate were harvested and blended, then transported to the winery of the University of La Rioja and stored for $12 \mathrm{~h}$ at $4.5^{\circ} \mathrm{C}$. Wine fermentations were conducted in $4 \mathrm{~L}$ of must according to the microscale fermentation set-up proposed by Sampaio et al. ${ }^{21}$ Grapes were destemmed and slightly crushed using a motorised grape crusher (Enomundi, Zaragoza, Spain). Sulfur dioxide was added at a rate of $60 \mathrm{mg} \mathrm{kg}^{-1}$ and musts were inoculated with yeast (Saccharomyces cerevisiae, Uvaferm 71B, Lallemand, Montreal, Canada) at a rate of $20 \mathrm{~g} \mathrm{hL}^{-1}$. Fermentation temperature was kept between 27 and $30^{\circ} \mathrm{C}$. Alcoholic fermentations were completed after 7 days, but extended maceration was allowed for a further 8 days. After fermentation, wines were manually racked off and pressed, and no malolactic fermentation was allowed. For each microfermentor the free-run and pressed wine fractions were blended and $40 \mathrm{mg} \mathrm{L}^{-1}$ sulfur dioxide was added prior to bottling. Five fermentations per treatment were conducted according to the five field replicates of 20-vine plots for each treatment.

\section{Must and wine analysis}

Musts and wines were analysed according to OIV methods. ${ }^{22} \mathrm{~A}$ wine sample of $125 \mathrm{~mL}$ was used to determine alcohol content, titratable acidity, $\mathrm{pH}$ and tartaric and malic acid concentrations. Colour density was calculated by adding the absorbance readings at 420, 520 and $620 \mathrm{~nm}$, while hue was determined as the ratio of absorbance readings at 420 and $520 \mathrm{~nm}$. Total polyphenol index was measured by the absorbance reading at $280 \mathrm{~nm}$ according to EEC methods. ${ }^{23}$ For each parameter, all analyses were run in triplicate 15 days after fermentation.

\section{Extraction and chromatographic analysis of wine volatiles}

To a $10 \mathrm{~mL}$ culture tube (Pyrex 1636/26MP, Lowell, USA), $8 \mathrm{~mL}$ of wine, $2.4 \mu \mathrm{g}$ of internal standard 4-nonanol (Merck 818773 , Darmstadt, Germany) and a magnetic stir bar (22.2 $\mathrm{mm} \times 4.8 \mathrm{~mm})$ were added. Extraction was done by stirring the sample with $400 \mu \mathrm{L}$ of dichloromethane (Merck 1.06054) for $15 \mathrm{~min}$. After cooling at $0{ }^{\circ} \mathrm{C}$ for $10 \mathrm{~min}$, the magnetic stir bar was removed and the organic phase was obtained by centrifugation $(2948 \times g, 5 \mathrm{~min}$, $4{ }^{\circ} \mathrm{C}$ ), with the extract being recovered in a vial using a Pasteur pipette. Then the aromatic extract was dried with anhydrous sodium sulfate (Merck 1.06649) and collected again in a new vial. ${ }^{24}$

A Chrompack CP-9000 (Chromapack International, Middelburg, The Netherlands) gas chromatograph equipped with a split/splitless injector and a flame ionisation detector together with a capillary column coated with CP-Wax 57 CB $(50 \mathrm{~m} \times$ $0.25 \mathrm{~mm}$ i.d., $0.2 \mu \mathrm{m}$ film thickness; Chrompack) was used. Injector and detector temperatures were both set at $250^{\circ} \mathrm{C}$. The oven temperature was maintained at $40^{\circ} \mathrm{C}$ for $5 \mathrm{~min}$, then programmed to rise from 40 to $235^{\circ} \mathrm{C}$ at $3^{\circ} \mathrm{C} \mathrm{min}^{-1}$ and finally from 235 to $255^{\circ} \mathrm{C}$ at $5^{\circ} \mathrm{C} \mathrm{min}^{-1}$. The carrier gas was helium 55 (Praxair, Maia,

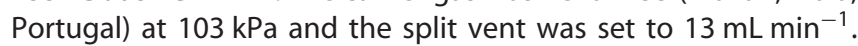
Each $3 \mu \mathrm{L}$ extract was injected in splitless mode (for $15 \mathrm{~s}$ ). Quantification of volatiles as 4-nonanol equivalents was performed with Varian MS Workstation Version 6.6 (Chromapack International, Middelburg, The Netherlands) by comparing retention indices with those of pure standard compounds and confirmed by gas chromatography/mass spectrometry. ${ }^{24}$

\section{Odour activity value}

To evaluate the contribution of each chemical compound to the aroma of the wine, the odour activity value (OAV) was determined. $\mathrm{OAV}$ is an indicator of the importance of a specific compound to the odour of a sample. It was calculated as the ratio between the concentration of an individual compound and the perception threshold found in the literature. ${ }^{25,26}$

\section{Statistical analysis}

The data were analysed using XLstat-Pro (2007 Version, Addinsoft, Paris, France). To test for significant differences in wine composition, analysis of variance (ANOVA) was applied. The effect of defoliation vs control, as well as the effect of timing and modality, was evaluated using a priori contrasts $(P<0.05)$. Dunnett's $t$ test ${ }^{27}$ was used to demonstrate significant differences between each defoliation treatment and the control. For interpreting the results, principal component analysis (PCA) on volatile compounds of Tempranillo wines was applied. 
Table 1. Influence of early defoliation on cluster exposure and canopy porosity in Tempranillo (Vitis vinifera L.) vines at harvest (mean values \pm standard errors in parentheses)

\begin{tabular}{lcc|} 
Treatment & $\begin{array}{c}\text { Cluster exposure } \\
\text { (pixels kg })^{-1} \text { ) }\end{array}$ & $\begin{array}{c}\text { Canopy porosity } \\
\text { (\% pixels) }\end{array}$ \\
\hline Control & $0.82(0.11)$ & $1.5(0.43)$ \\
Man-PB & $\mathbf{1 . 9 9}(0.52)$ & $\mathbf{5 . 8}(0.81)$ \\
Man-FS & $\mathbf{1 . 6 4}(0.17)$ & $\mathbf{8 . 6}(1.47)$ \\
Mec-PB & $\mathbf{2 . 8 0}(0.39)$ & $\mathbf{1 2 . 8}(1.56)$ \\
Mec-FS & $1.02(0.19)$ & $1.5(0.43)$ \\
Contrast P values & & $<0.001$ \\
Control vs defoliated & $<0.001$ & $<0.001$ \\
Control vs pre-bloom & $<0.001$ & $<0.001$ \\
Control vs fruit set & 0.127 & 0.079 \\
Pre-bloom vs fruit set & 0.001 & 0.062 \\
Manual vs mechanical & 0.758 & $<0.001$ \\
Analysis of variance P values & & \\
Treatment & $<0.001$ & \\
\hline Means in bold type are significantly different from the control at \\
$P \leq 0.05$ (Dunnett's test). & & \\
\hline
\end{tabular}

\section{RESULTS AND DISCUSSION}

Cluster exposure and canopy porosity increased significantly in early defoliated vines (Table 1). These effects were more pronounced in pre-bloom leaf-pulled vines than in those defoliated at fruit set. Studies performed on Sangiovese and Trebbiano vines also showed that hand and mechanical defoliation significantly reduced fruit set, bunch compactness and yield. ${ }^{1,2}$ Furthermore, canopy porosity was improved by early leaf removal in Graciano and Carignan vines. ${ }^{3}$ These results indicated that early defoliation may affect the fruit microclimate during grape berry development, from fruit set to harvest. Table 2 shows the influence of the defoliation treatments on the total soluble solids and acidity parameters of the musts. Early leaf removal resulted in musts richer in total soluble solids and almost no differences in acidity, with the effects being more intense for pre-bloom treatments. Similar findings, of more ripened fruit in terms of increased total soluble solids in grapes corresponding to early defoliated vines, were also observed in other varieties..$^{1-3}$

Table 3 shows the influence of the defoliation treatments on the oenological parameters of the wines, which were in close agreement with the values of the total soluble solids and acidity parameters determined in the musts. In general, early leaf removal led to wines of higher alcohol content, more intensely coloured and with a larger total polyphenol index, whereas $\mathrm{pH}$, titratable acidity, malic acid and hue remained generally unaffected.

Pre-bloom leaf removal increased the ethanol concentration in Tempranillo wines more than fruit set intervention. Regarding the method of defoliation, mechanical treatments induced the enhancement of colour intensity and total polyphenol index as compared with control wines. These results coincide with Diago et al., ${ }^{11}$ who reported that mechanical defoliation was more effective in reducing yield, cluster weight and number of berries than manual leaf pulling, by affecting the fruit microclimate.

Table 4 shows the influence of the defoliation treatments on the concentration of 25 volatile compounds grouped in different families: $C_{6}$ compounds, alcohols, ethyl esters, acetates, volatile acids and terpenes. The main volatile compounds were $2-+$ 3-methyl-1-butanol, 2-phenylethanol and 2-methyl-1-propanol;
Table 2. Influence of early defoliation on total soluble solids and acidity parameters of Tempranillo (Vitis vinifera L.) musts in season 2008 (mean values \pm standard errors in parentheses)

\begin{tabular}{|lccc|} 
Treatment & $\begin{array}{c}\text { Total soluble } \\
\left.\text { solids ( }{ }^{\circ} \mathrm{Brix}\right)\end{array}$ & $\mathrm{pH}$ & $\begin{array}{c}\text { Titratable } \\
\text { acidity } \\
\left(\mathrm{g} \mathrm{L}^{-1} \mathrm{TH}_{2}\right)\end{array}$ \\
\hline Control & $22.0(0.65)$ & $3.10(0.01)$ & $5.40(0.35)$ \\
Man-PB & $\mathbf{2 4 . 3 ( 0 . 3 8 )}$ & $3.08(0.02)$ & $5.52(0.28)$ \\
Man-FS & $23.0(0.33)$ & $2.99(0.01)$ & $5.34(0.22)$ \\
Mec-PB & $\mathbf{2 5 . 0 ( 0 . 2 1 )}$ & $3.14(0.02)$ & $4.76(0.27)$ \\
Mec-FS & $\mathbf{2 3 . 5}(0.38)$ & $3.07(0.04)$ & $4.86(0.27)$ \\
Contrast P values & & & \\
Control vs defoliated & $<0.001$ & 0.282 & 0.386 \\
Control vs pre-bloom & $<0.001$ & 0.727 & 0.461 \\
Control vs fruit set & 0.024 & 0.028 & 0.396 \\
Pre-bloom vs fruit set & 0.003 & 0.003 & 0.888 \\
Manual vs mechanical & 0.209 & 0.005 & 0.040 \\
Analysis of variance P values & & & \\
Treatment & $<0.001$ & 0.003 & 0.049 \\
\hline
\end{tabular}

Means in bold type are significantly different from the control at $P \leq 0.05$ (Dunnett's test).

however, these volatile compounds did not show significant differences among defoliation treatments.

Early leaf removal only modified the total concentrations of $\mathrm{C}_{6}$ compounds and acetates, whereas ethyl esters, volatile acids, alcohols and terpenes in the wines remained generally unaffected (Table 5). Reynolds and Wardle ${ }^{28}$ found that basal leaf removal led to increased free volatiles in wines from several white grape cultivars. The most direct effects of canopy management on fruit quality have been observed with cluster zone leaf removal, which increased total monoterpene accumulation in Gewürztraminer and Muscat. ${ }^{29,30}$ These studies of several vineyard management techniques suggest a link between sunlight exposure and increased monoterpenes in V. vinifera. Zoecklein et al. ${ }^{17}$ found higher concentrations of selected bound monoterpene alcohols (geraniol, nerol and linalool) and bound aromatic alcohols (benzyl alcohol and 2-phenylethanol) in fruits of leaf-removed canopies than in those of control canopies.

Interestingly, the effects of early defoliation were mostly observed in the $C_{6}$ compound and acetate families. Early defoliation induced a significant reduction in $\mathrm{C}_{6}$ compounds and increased the concentrations of acetates in the wines (Table 5). In this regard, significant variation was observed for (Z)-3-hexen1-ol, 3-methylbutyl acetate and 2-phenylethyl acetate (Table 4). The effect of early defoliation on the volatile composition of Tempranillo wines was mainly observed when leaf pulling was conducted at pre-bloom. These results were correlated with total soluble solids, with greater values being shown in musts where the defoliation treatment was performed at pre-bloom, as can be observed in Table 2.

In addition to the above-mentioned compounds, the concentrations of 1-hexanol, 3-methyl-1-pentanol and ethyl octanoate were also affected by pre-bloom leaf removal. It is well known that $C_{6}$ aldehydes derive from grape polyunsaturated fatty acids from membrane lipids, which are subsequently reduced to $C_{6}$ alcohols, which can in turn be esterified to produce esters. ${ }^{24}$ Slight differences in the amounts of (E)-3-hexen-1-ol and (Z)-3-hexen1 -ol have been described by several authors according to terroir and cultural practices. ${ }^{2,31,32}$ Tempranillo wines showed larger 
Table 3. Influence of early defoliation on oenological parameters of Tempranillo wine in season 2008. Mean values, standard errors, analysis of variance and contrasts' significance are shown

\begin{tabular}{|c|c|c|c|c|c|c|c|}
\hline Treatment & Ethanol (\% v/v) & $\mathrm{pH}$ & $\begin{array}{l}\text { Titratable acidity } \\
\qquad\left(\mathrm{g} \mathrm{L}^{-1} \mathrm{TH}_{2}\right)\end{array}$ & $\begin{array}{l}\text { Malic acid } \\
\quad\left(\mathrm{g} \mathrm{L}^{-1}\right)\end{array}$ & Colour density & Hue & $\begin{array}{l}\text { Total polyphenol } \\
\text { index }\end{array}$ \\
\hline Control & $12.8(0.23)$ & $3.82(0.04)$ & $5.23(0.23)$ & $3.04(0.45)$ & $10.1(0.90)$ & $0.68(0.05)$ & $46.0(5.03)$ \\
\hline Man-PB & $13.5(0.15)$ & $3.86(0.05)$ & $5.94(0.22)$ & $3.21(0.09)$ & $12.3(1.05)$ & $0.74(0.02)$ & $53.5(2.46)$ \\
\hline Man-FS & $13.2(0.08)$ & $3.83(0.02)$ & $5.70(0.02)$ & $2.83(0.23)$ & $11.6(1.01)$ & $0.62(0.03)$ & $47.2(1.33)$ \\
\hline Mec-PB & $13.3(0.15)$ & $3.97(0.06)$ & $5.22(0.16)$ & $3.04(0.05)$ & $15.3(1.17)$ & $0.76(0.02)$ & $60.5(3.49)$ \\
\hline Mec-FS & $13.2(0.05)$ & $3.89(0.07)$ & $5.45(0.17)$ & $2.59(0.39)$ & $15.9(1.57)$ & $0.64(0.53)$ & $55.1(5.12)$ \\
\hline \multicolumn{8}{|c|}{ Contrasts' significance $\mathrm{P}$ values } \\
\hline Control vs defoliated & 0.004 & 0.249 & 0.213 & 0.646 & 0.006 & 0.824 & 0.061 \\
\hline Control vs pre-bloom & $<0.001$ & 0.143 & 0.249 & 0.752 & 0.011 & 0.085 & 0.020 \\
\hline Control vs fruit set & 0.051 & 0.526 & 0.264 & 0.259 & 0.013 & 0.191 & 0.277 \\
\hline Pre-bloom vs fruit set & 0.686 & 0.322 & 0.988 & 0.085 & 0.991 & $<0.001$ & 0.131 \\
\hline $\begin{array}{l}\text { Manual vs mechanical } \\
\text { Analysis of variance } P \text { v }\end{array}$ & 0.791 & 0.100 & 0.057 & 0.391 & 0.003 & 0.506 & 0.049 \\
\hline Treatment & 0.030 & 0.075 & $<0.001$ & 0.151 & 0.024 & 0.010 & 0.045 \\
\hline
\end{tabular}

Table 4. Influence of early defoliation on volatile compounds of Tempranillo wines (mean values, $\mu \mathrm{g} \mathrm{L}^{-1}$ )

\begin{tabular}{|c|c|c|c|c|c|c|c|c|c|c|c|}
\hline \multirow[b]{2}{*}{ Compound } & \multirow[b]{2}{*}{ Family type } & \multicolumn{5}{|c|}{ Treatments } & \multicolumn{5}{|c|}{ Contrast $P$ values } \\
\hline & & Control & Man-PB & Man-FS & Mec-PB & Mec-FS & $\begin{array}{l}\text { Control vs } \\
\text { defoliated }\end{array}$ & $\begin{array}{l}\text { Control vs } \\
\text { pre-bloom }\end{array}$ & $\begin{array}{c}\text { Control } \\
\text { vs } \\
\text { fruit set }\end{array}$ & $\begin{array}{c}\text { Pre-bloom } \\
\text { vs } \\
\text { Fruit set }\end{array}$ & $\begin{array}{l}\text { Manual vs } \\
\text { mechanical }\end{array}$ \\
\hline 1-Hexanol & $\mathrm{C}_{6}$ compounds & 847 & 633 & 717 & 578 & 780 & 0.084 & 0.020 & 0.339 & 0.043 & 0.914 \\
\hline (E)-3-Hexen-1-ol & & 24 & 20 & 17 & 19 & 23 & 0.273 & 0.269 & 0.386 & 0.764 & 0.402 \\
\hline (Z)-3-Hexen-1-ol & & 94 & 65 & 74 & 52 & 85 & 0.026 & 0.002 & 0.182 & 0.010 & 0.941 \\
\hline 1-Propanol & Alcohols & 154 & 114 & 854 & 200 & 221 & 0.423 & 0.989 & 0.104 & 0.039 & 0.178 \\
\hline 2-Methyl-1-propanol & & 3519 & 2874 & 3975 & 2830 & 4118 & 0.911 & 0.461 & 0.559 & 0.096 & 0.882 \\
\hline 1-Butanol & & 243 & 230 & 427 & 248 & 264 & 0.632 & 0.961 & 0.322 & 0.179 & 0.410 \\
\hline $\begin{array}{l}\text { 2- + 3-Methyl-1- } \\
\text { butanol }\end{array}$ & & 32370 & 26014 & 31429 & 22977 & 33055 & 0.450 & 0.169 & 0.995 & 0.082 & 0.931 \\
\hline 3-Methyl-1-pentanol & & 36 & 23 & 34 & 16 & 31 & 0.112 & 0.009 & 0.560 & 0.008 & 0.364 \\
\hline 2-Phenylethanol & & 6357 & 6269 & 6137 & 7223 & 6823 & 0.714 & 0.645 & 0.851 & 0.728 & 0.207 \\
\hline Ethyl butyrate & Ethyl esters & 57 & 76 & 57 & 46 & 61 & 0.741 & 0.703 & 0.836 & 0.826 & 0.090 \\
\hline $\begin{array}{l}\text { Ethyl } \\
\text { 2-methylbutyrate }\end{array}$ & & 553 & 509 & ND & 723 & 848 & 0.832 & 0,968 & 0,720 & 0,677 & 0.007 \\
\hline Ethyl hexanoate & & 64 & 61 & 64 & 59 & 67 & 0.942 & 0.752 & 0.835 & 0.499 & 0.952 \\
\hline Ethyl lactate & & 789 & 419 & 502 & 389 & 925 & 0.301 & 0.090 & 0.813 & 0.041 & 0.272 \\
\hline Ethyl octanoate & & 6 & 14 & 19 & 17 & ND & 0.134 & 0.028 & 0.507 & 0.042 & 0.014 \\
\hline Diethyl succinate & & 245 & 239 & 149 & 193 & 125 & 0.110 & 0.451 & 0.010 & 0.013 & 0.245 \\
\hline $\begin{array}{l}\text { 3-Methylbutyl } \\
\text { acetate }\end{array}$ & Acetates & 62 & 341 & 176 & 219 & 67 & 0.044 & 0.005 & 0.247 & 0.023 & 0.110 \\
\hline Hexyl acetate & & 9 & 8 & ND & 16 & ND & 0.486 & 0.305 & 0.003 & $<0.001$ & 0.306 \\
\hline $\begin{array}{l}\text { 2-Phenylethyl } \\
\text { acetate }\end{array}$ & & 325 & 528 & 350 & 611 & 395 & 0.030 & 0.002 & 0.479 & 0.001 & 0.431 \\
\hline $\begin{array}{l}\text { 2- + 3-Methylbutyric } \\
\text { acid }\end{array}$ & Volatile acids & 54 & 45 & 37 & 36 & ND & 0.048 & 0.231 & 0.004 & 0.014 & 0.014 \\
\hline Hexanoic acid & & 133 & 129 & 96 & 183 & 196 & 0.420 & 0.426 & 0.515 & 0.859 & $<0.001$ \\
\hline Octanoic acid & & 88 & 95 & 79 & 243 & 195 & 0.190 & 0.159 & 0.340 & 0.553 & 0.001 \\
\hline Decanoic acid & & ND & 16 & ND & 90 & 77 & 0.037 & 0.037 & 0.091 & 0.585 & $<0.001$ \\
\hline Linalool & Terpenes & 11 & 9 & 8 & 12 & 12 & 0.808 & 0.814 & 0.842 & 0.966 & 0.110 \\
\hline
\end{tabular}


Table 5. Influence of early defoliation on volatile composition of Tempranillo wines (mean values, $\mu \mathrm{g} \mathrm{L}^{-1}$ )

\begin{tabular}{|c|c|c|c|c|c|c|c|c|c|c|}
\hline \multirow[b]{2}{*}{$\begin{array}{l}\text { Compound } \\
\text { family }\end{array}$} & \multicolumn{5}{|c|}{ Treatments } & \multicolumn{5}{|c|}{ Contrast $P$ values } \\
\hline & Control & Man-PB & Man-FS & Mec-PB & Mec-FS & $\begin{array}{c}\text { Control } \\
\text { vs } \\
\text { defoliated }\end{array}$ & $\begin{array}{c}\text { Control } \\
\text { vs } \\
\text { pre-bloom }\end{array}$ & $\begin{array}{c}\text { Control } \\
\text { vs } \\
\text { fruit set }\end{array}$ & $\begin{array}{c}\text { Pre-bloom } \\
\text { vs } \\
\text { fruit set }\end{array}$ & $\begin{array}{c}\text { Manual } \\
\text { vs } \\
\text { mechanical }\end{array}$ \\
\hline $\mathrm{C}_{6}$ compounds & 966 & 714 & 808 & 649 & 889 & 0.075 & 0.017 & 0.317 & 0.058 & 0.906 \\
\hline Alcohols & 42678 & 35522 & 42857 & 33495 & 44511 & 0.576 & 0.245 & 0.876 & 0.096 & 0.969 \\
\hline Ethyl esters & 1714 & 1319 & 791 & 1427 & 2026 & 0.354 & 0.289 & 0.547 & 0.555 & 0.047 \\
\hline Acetates & 397 & 878 & 526 & 845 & 462 & 0.028 & $<0.001$ & 0.243 & $<0.001$ & 0.723 \\
\hline Volatile acids & 275 & 285 & 212 & 551 & 468 & 0.197 & 0.134 & 0.403 & 0.382 & $<0.001$ \\
\hline Terpenes & 11 & 9 & 8 & 12 & 12 & 0.808 & 0.814 & 0.842 & 0.966 & 0.110 \\
\hline
\end{tabular}

contents of (Z)-3-hexenol when compared with wines of other varieties such as Cabernet Sauvignon and Monastrell. ${ }^{33}$ Among the free volatile compounds, a rather low content of $C_{6}$ alcohols, with a prevalence of $(Z)$-3-hexen-1-ol over the $(E)$ isomer and sometimes a remarkable level of $(E)$-2-hexen-1-ol, seems to be typical for the variety Tannat. ${ }^{34}$ However, these compounds decrease during grape ripening. In our study the level of these compounds showed a significant decrease when defoliation was applied. These results were in close agreement with total soluble solids ( ${ }^{\circ}$ Brix) (Table 2), because the greater the level of total soluble solids, the lower the level of $C_{6}$ compounds, confirming the decrease in these compounds during ripening. $C_{6}$ compounds showed $a$ similar trend until veraison in Cabernet Sauvignon grapes, but the levels of 1-hexanol increased steadily and significantly after veraison, whereas there was a less pronounced increase in (Z)-3hexen-1-ol and a significant drop in concentration towards late berry development. ${ }^{35}$

An interesting outcome related to the timing of defoliation was that hexyl acetate was not detected in the fruit set defoliation wines (Table 4). Regarding the method of defoliation, significant differences in the concentrations of some ethyl esters (ethyl2-methylbutyrate and ethyl octanoate) and all studied volatile acids were observed in the wines corresponding to manual and mechanical treatments (Tables 4 and 5).

Quantitatively, alcohols were the largest group of volatile compounds, accounting for more than $90 \%$ of the total volatile concentration in all defoliation treatments, followed by ethyl esters. Higher alcohols and ethyl esters produced during alcoholic fermentation play an important role in the flavour of wines, depending on the type of compound and concentration. ${ }^{36}$ Kozina et al. ${ }^{37}$ showed no differences in higher alcohol concentrations between control and classical leaf removal (applied at veraison) wines of Sauvignon Blanc and Riesling cultivars. A study carried out by Bubola et al. ${ }^{38}$ suggested that basal leaf removal before bloom led to higher contents of volatile esters and higher alcohols than control wines but lower contents of monoterpene alcohols in Istrian Malvasia wines.

In that same study the concentration of volatile acids in wines made from defoliated vines was altered as compared with control wines. In another trial conducted on Sauvignon Blanc, eight leaves per shoot were removed manually and the wines from these vines had the lowest amount of fatty acids and volatile esters with respect to control (non-defoliated) wines. ${ }^{37}$ Furthermore, Miele et al..$^{39}$ showed that the removal of all leaves below the clusters at the beginning of bloom led to higher concentrations

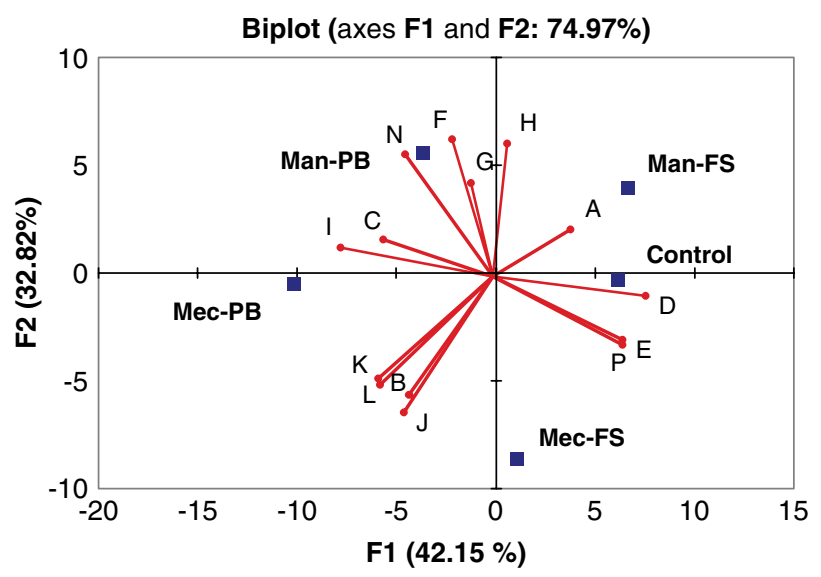

Figure 1. Principal component analysis of Tempranillo wines from different early defoliation treatments. Volatile compounds: A, 1-propanol; B, ethyl2-methylbutyrate; C, hexyl acetate; D, 3-methyl-1-pentanol; E, (Z)-3-hexen1-ol; F, ethyl octanoate; $\mathrm{G}$, diethyl succinate; $\mathrm{H}, 2-+3$-methylbutyric acid; I, 2-phenylethyl acetate; J, hexanoic acid; K, octanoic acid; L, decanoic acid; N, 3-methylbutyl acetate; P, 1-hexanol.

of 3-methyl-1-butanol and 2-methyl-1-propanol in the wines, this being considered a very good alternative for the production of quality Merlot wines.

Terpenes constitute an important group of volatile compounds in several white grape varieties, such as Muscat and Gewürztraminer. In our study, only linalool was identified and quantified in the red wines of Tempranillo at low concentrations. and it was not significantly affected by early defoliation, despite the improvement in canopy porosity and cluster exposure. Terpenes have been shown to be sensitive to sun exposure. $28,30,40,41$ Reynolds and Wardle ${ }^{28}$ reported that classical leaf removal, leading to improved cluster exposure and hence better sunlight penetration into the canopy, favoured the enhancement of volatile terpenes in several white grape varieties. Linalool appeared to be most sensitive to sun exposure. ${ }^{30}$

With the aim of better interpreting the results, PCA was applied to the volatile compounds showing significant differences among wines from the different defoliation treatments (Fig. 1). The first two principal components, PC1 and PC2, accounted for $74.97 \%$ of the total variance in the data ( 42.15 and $32.82 \%$ respectively). PC1 was characterised by major contributions from (Z)-3-hexenol, 3-methyl-1-pentanol and 1-hexanol on the positive side and 2-phenylethyl acetate, decanoic acid, hexanoic acid and hexyl 
Table 6. Odour activity values of volatile compounds in Tempranillo wines from different early defoliation treatments

\begin{tabular}{|c|c|c|c|c|c|c|c|c|c|}
\hline \multirow[b]{2}{*}{ Compound } & \multirow[b]{2}{*}{ Family type } & \multirow{2}{*}{$\begin{array}{l}\text { Odour threshold } \\
\qquad\left(\mu g \mathrm{~L}^{-1}\right)\end{array}$} & \multirow[b]{2}{*}{ Odour descriptor ${ }^{a}$} & \multirow[b]{2}{*}{ Control } & \multicolumn{4}{|c|}{ Odour activity values } & \multirow[b]{2}{*}{ Sig. ${ }^{\mathrm{b}}$} \\
\hline & & & & & Man-PB & Man-FS & Mec-PB & Mec-FS & \\
\hline Ethyl-2-methylbutyrate & Ethyl esters & 18 & Fruity & $30.72 a$ & $28.29 a$ & $0.00 \mathrm{~b}$ & $40.19 a$ & $47.13 a$ & $* *$ \\
\hline Ethyl octanoate & & 5 & Apple, sweetish & $1.14 \mathrm{a}$ & $2.97 \mathrm{~b}$ & $3.87 \mathrm{~b}$ & $3.35 b$ & $0.00 c$ & $* * *$ \\
\hline 2-Phenylethyl acetate & Acetates & 250 & Rose, honey & $1.30 a$ & $2.11 \mathrm{~b}$ & $1.40 \mathrm{a}$ & $2.44 b$ & $1.58 \mathrm{a}$ & $* *$ \\
\hline 3-Methylbutyl acetate & & 30 & Banana & $2.08 a$ & $11.38 \mathrm{~b}$ & $5.87 a$ & $7.29 a$ & $2.25 \mathrm{a}$ & $*$ \\
\hline 2- + 3-Methylbutyric acid & Volatile acids & 34 & Cheese, old hops & $1.59 \mathrm{a}$ & $1.31 \mathrm{a}$ & $1.10 \mathrm{a}$ & $1.05 a$ & $0.00 \mathrm{~b}$ & $* * *$ \\
\hline Hexanoic acid & & 420 & Cheese, sweaty & $4.42 a$ & $4.29 a$ & $3.20 \mathrm{a}$ & $6.09 \mathrm{~b}$ & $6.54 b$ & $* * *$ \\
\hline \multicolumn{10}{|c|}{$\begin{array}{l}\text { Mean values within columns were separated by least significant difference test }(P=0.05) \text {. Dissimilar letters across a row of treatment means indicate } \\
\text { a statistically significant difference between those means. } \\
\text { a Odour thresholds and odour descriptors as reported in the literature. } \\
\text { b Statistical significance of treatments: }{ }^{*} P=0.05 ;{ }^{* *} P=0.01 ;{ }^{* * *} P=0.001 .\end{array}$} \\
\hline
\end{tabular}

acetate on the negative side. For PC2, ethyl octanoate, 2- + 3methylbutyric acid and 3-methylbutyl acetate showed positive loadings, whereas ethyl-2-methylbutyrate and hexanoic acid exhibited negative loadings. PC1 classifies the wines according to phenological stages. Fruit set defoliation treatment and control wines were sited on the positive side of PC1, characterised by alcohols and $C_{6}$ compounds, while pre-bloom defoliation treatment wines were located on the negative side of PC1, characterised by acetate and ester compounds. PC2 helps to classify the wines according to the method of defoliation. In this regard, control and manual defoliation treatment wines were located on the positive side of the axis, whereas mechanical defoliation treatment wines were located on the negative side.

In order to assess the influence of the compounds studied on overall wine aroma, OAV was calculated as the ratio of the concentration of each compound to its perception threshold. Only compounds with OAV > 1 are said to contribute individually to wine aroma. ${ }^{42}$ However, a particular compound with OAV $<1$ might also contribute to the aroma of a wine because of the additive effect of similar compounds (similar structure or odour). ${ }^{25}$ OAVs were first calculated for the compounds exhibiting significant differences among wines. Of these, only six volatile compounds presented OAV > 1 (Table 6). In our study, ethyl-2-methylbutyrate (fruity aroma), ethyl octanoate (apple aroma), 2- + 3-methylbutyric acid (cheese aroma), 2phenylethyl acetate (rose aroma), hexanoic acid (vegetable aroma) and 3-methylbutyl acetate (banana aroma) have been shown to contribute significantly to Tempranillo wine aroma. The highest OAV was represented by ethyl-2-methylbutyrate (fruity aroma) for Tempranillo wines from all defoliation treatments except manual defoliation at pre-bloom, where the highest OAV value corresponded to ethyl octanoate (apple, sweetish). Mechanical treatments (pre-bloom and fruit set) showed higher values of ethyl-2-methylbutyrate than the control. In sensory analysis of Tempranillo wines from the 2008 vintage ${ }^{11}$ the most frequent attributes were also fruity aromas, and their overall frequencies across the four defoliation treatments were higher than those of the control. Diago et al. ${ }^{11}$ also showed that both yield reduction and increased cluster exposure induced by early defoliation modified the final wine aroma properties of Tempranillo wines determined by sensory analysis. Moreover, when Botrytis infection existed, wines corresponding to the early leaf removal treatments were found to be more intensely perceived in fruity aromas and less intensely in dried fruit notes. These outcomes were related to the significant decrease in Botrytis incidence observed in the fruit from defoliated vines (ranging from 1.6 to $6.7 \%$ ) as compared with the control (14.6\% Botrytis infection). ${ }^{11}$ In the Diago et al. ${ }^{11}$ study the trained panel did not perceive any earthy or mouldy aroma in Tempranillo wines. These aromas are typical in wines made from rotten and fungus-affected fruit. Therefore the volatile compounds responsible for these earthy or mouldy off-odours, such as geosmin, methyl isoborneol, 1-octen-3-ol and fenchol, ${ }^{43-45}$ among others, were not targeted in our study.

(Z)-3-Hexen-1-ol (green, herbaceous descriptor) and octanoic acid do not appear to have contributed individually to the aroma of Tempranillo wines in this study. However, the contribution of compounds with near-unity OAVs to wine aroma cannot be ignored, because they can enhance some existing notes through synergy with other compounds. ${ }^{46}$ In the Diago et al. ${ }^{11}$ study the cut grass descriptor was detected by the wine tasters and it showed higher values for mechanical defoliation than for the control.

The floral character of Tempranillo wines (2008 vintage) is also shown in both studies, violet by the sensory study ${ }^{11}$ and 2-phenylethyl acetate (rose descriptor) by the present study. In both cases the floral character showed higher values for defoliation treatments than for the control.

\section{CONCLUSIONS}

The results of this study suggest that early leaf removal may induce significant changes in the concentration of volatile compounds in Tempranillo wines. Changes in agronomic parameters leading to improved fruit exposure may have a positive effect on the volatile composition of the wines. The highest values for cluster exposure and canopy porosity found for early defoliation treatments compared with non-defoliated vines were correlated with the highest concentration of total acetates, some volatile acids and (Z)-3-hexen-1-ol. Wines from defoliation treatments were mainly characterised by fruity and floral aroma versus the control. It can be concluded that early leaf removal may modify wine aroma quality.

\section{ACKNOWLEDGEMENTS}

We thank the Agencia de Desarrollo Económico de La Rioja (ADER) and the Ministerio de Ciencia e Innovación for their financial support (ADER-2006-I-ID-00157 and AGL2007-60378 respectively). We would also like to thank the Agrupación de Bodegas Centenarias y Tradicionales de Rioja ( $A B C$ ) and New 
Holland for their assistance and help. Dr Vilanova is grateful to the 'Isidro Parga Pondal' programme financed by the Xunta de Galicia (Spain).

\section{REFERENCES}

1 Poni S, Casalini L, Bernizzoni F, Civardi S and Intrieri C, Effects of early defoliation on shoot photosynthesis, yield components, and grape composition. Am J Enol Vitic 57:397-407 (2006).

2 Intrieri C, Filippetti I, Allegro G, Centinari M and Poni S, Early defoliation (hand vs mechanical) for improved crop control and grape composition in Sangiovese (Vitis vinifera L.). Aust J Grape Wine Res 14:25-32 (2008)

3 Tardaguila J, Martinez de Toda F, Poni S and Diago MP, Early leaf removal impact on yield components, fruit and wine composition of Graciano and Carignan grapevines. Am J Enol Vitic 61:372-381 (2010).

4 Wolf TK, Pool RM and Matick LR, Responses of young Chardonnay grapevines to shoot tipping, ethephon, and basal leaf removal. Am J Enol Vitic 37:263-268 (1986).

5 Bledsoe AM, Kliewer WM and Marois JJ, Effects of timing and severity of leaf removal on yield and fruit composition of Sauvignon blanc grapevines. Am J Enol Vitic 39:49-54 (1988).

6 Percival DC, Fisher KH and Sullivan JS, Use of fruit zone leaf removal with Vitis vinifera L. cv. Riesling grapevines. I. Effect on canopy structure, microclimate, bud survival, shoot density and vine vigor. Am J Enol Vitic 45:123-132 (1994).

7 Staff SL, Percival DC, Sullivan JA and Fisher KH, Fruit zone leaf removal influences vegetative, yield, disease, fruit composition and wine sensory attributes of Vitis vinifera L. Optima and Cabernet franc. Can J Plant Sci 77:149-153 (1997).

8 Hunter JJ, De Villiers OT and Watts JE, The effect of partial defoliation on quality characteristic of Vitis vinifera L.cv. Cabernet Sauvignon grapes. II. Skin color, skin sugar, and wine quality. Am J Enol Vitic 42:13-18 (1991)

9 Tardaguila J, Diago MP, Martinez de Toda F, Poni S and Vilanova $M$, Effects of timing of leaf removal on yield, berry maturity, wine composition and sensory properties of cv Grenache grow under non irrigated conditions. J Int Vigne Vin 42:221 - 229 (2008).

10 Poni S, Bernizzoni F, Civardi S and Libelli N, Effects of pre-bloom leaf removal on growth of berry tissues and must composition in two red Vitis vinifera L. cultivars. Aust J Grape Wine Res 15:185-193 (2009).

11 Diago MP, Vilanova M and Tardaguila J, Effects of timing of early defoliation (manual and mechanical) on the aroma attributes of Tempranillo (Vitis vinifera L.) wines. Am J Enol Vitic 61:382-391 (2010).

12 Dunlevy JD, Kalua CM, Keyzers RA and Boss PK, The production of flavour and aroma compounds in grape berries, in Grapevine Molecular Physiology and Biotechnology (2nd edn), ed. by Roubelakis-Angelakis KA. Springer Science, Berlin, Germany, pp. 293-340 (2009)

13 Rap A and Mandery $H$, Wine aroma. Experientia 42:873-884 (1986).

14 Aznar M, López R, Cacho JF and Ferreira V, Identification and quantification of impact odorants of aged red wines from Rioja. GC-olfactometry, quantitative GC-MS and odor evaluation of HPLC fractions. J Agric Food Chem 48:2924-2929 (2001).

15 Ferreira V, Ortín N, Escudero A, López R and Cacho J, Chemical characterization of the aroma of Grenache rosé wines. Aroma extract dilution analysis, quantitative determination and sensory reconstitution studies. J Agric Food Chem 50:4048-4054 (2002).

16 Reynolds AG and Wardle DA, Flavour development in the vineyard: impact of viticultural practices on grape monoterpenes and their relationship to wine sensory response. S Afr J Enol Vitic 18:3-18 (1997).

17 Zoecklein BW, Wolf TK, Marcy JE and Jasinki Y, Effect of fruit zone leaf thinning on total glycosides and selected aglycone concentrations of Riesling (Vitis vinifera L.) grapes. Am J Enol Vitic 49:35-46 (1998).

18 Roberts RW, Reynolds AG and De Savigni C, Composition and wine sensory attributes of Chardonay Musque from different viticultural treatments: implications for a winegrape quality model. Int J Food Sci 7:57-83 (2007).

19 Ristic R, Downey MO, Iland PG, Bindon K, Francis IL, Herderich M, et al, Exclusion of sunlight from Shiraz grapes alters wine colour, tannins and sensory properties. Aust J Grape Wine Res 13:53-65 (2007).
20 Coombe BG, Adoption of a system for identifying grapevine growth stages. Aust J Grape Wine Res 1:104-110 (1995).

21 Sampaio TL, Kennedy JA and Vasconcelos MC, Use of microscale fermentations in grape and wine research. Am J Enol Vitic 58:534-539 (2007)

22 OIV, Recueildes Méthodes Internationales d'Analyse des Vins et des Moûts. Organisation Internationale de la Vigne et du Vin, Paris (1990).

23 EEC, Commission Regulation (EC) No. 2676 of 1 September 1990 determining Community methods for the analysis of wines. Off J Eur Union L272:1 - 292 (1990).

24 Oliveira JM, Faria M, Sá F, Barros F and Araújo IM, C6-alcohols as varietal markers for assessment of wine origin. Anal Chim Acta 563:300-309 (2006).

25 Francis IL and Newton JL, Determining wine aroma from compositional data. Aust J Grape Wine Res 11:114-126 (2005).

26 Vilanova M, Genisheva Z, Bescansa L, Masa A and Oliveira JM, Volatile composition of wines from Vitis vinifera Agudelo, Serradelo and Blanco lexítimo from Betanzos (NW Spain). J Inst Brew 115:35-40 (2009).

27 Dunnett CW, A multiple comparison procedure for comparing several treatments with a control. J Am Statist Assoc 50:1096-1121 (1955).

28 Reynolds AG and Wardle DA, Influence of fruit microclimate on monoterpene levels of Gewürztraminer. Am J Enol Vitic 40:149-154 (1989).

29 Belancic A, Agosin E, Ibacache A, Bordeu E, Baumes R, Razungles $A$, et al, Influence of sun exposure on the aromatic composition of Chilean Muscat grape cultivars Moscatel de Alejandría and Moscatel rosado. Am J Enol Vitic 48:181 - 186 (1997)

30 Reynolds AG, Yerle S, Watson B, Price SF and Wardle DA, Fruit environment and crop level effects on Pinot Noir. III. Composition and descriptive analysis of Oregon and British Columbia wines. Am J Enol Vitic 47:329-339 (1996).

31 Nicolini G, Versini G, Amadei E and Marchio M, 3-Hexen-1-ol isomers in Muller-Thurgau wines, a varietal characteristic affected by must sulfiting time. Vitis 35:147-148 (2006).

32 Moio L, Ugliano M, Genovese A, Gambuti A, Pessina R and Piombino $P$, Effect of antioxidant protection of must on volatile compounds and aroma shelf life of Falanghina (Vitis vinifera L.) wine. J Agric Food Chem 52:891-897 (2004).

33 Aleixandre L, Lizama V, Alvarez I and García MJ, Varietal differentiation of red wines in the Valencian region (Spain). J Agric Food Chem 50:751 - 755 (2002)

34 Boido E, Lloret A, Medina K, Fariña L, Carrau F, Versini G, et al, Aroma composition of Vitis vinifera $\mathrm{Cv}$. tannat: the typical red wine from Uruguay. J Agric Food Chem 51:5408-5413 (2003).

35 Kalua CM and Boss PK, Evolution of volatile compounds during the development of Cabernet Sauvignon grapes (Vitis vinifera L.). J Agric Food Chem 57:3818-3830 (2009).

36 Gomez-Miguez MJ, Cacho JF, Ferreira V, Vicario IM and Heredia FJ, Volatile components of Zalema white wines. Food Chem 100:1464-1473 (2007)

37 Kozina B, Karoglan M, Herjavec S, Jeromel A and Orlic S, Influence of basal leaf removal on the chemical composition of Sauvignon Blanc and Riesling wines. J Food Agric Environ 6:28-33 (2008).

38 Bubola M, Persurie D, Ganié KK and Cossetto $M$, Influence of timing and intensity of basal leaf removal on aromatic composition of cv. Istrian Malvasia wines. Abstracts Book III Int. Symp. 'Malvasias', Canary Islands, pp. 64-65 (2009).

39 Miele A, Rizzon LA and Mandelli F, Grapevine canopy management effects on Merlot wine composition. Pesq Agropec Bras 44:463-470 (2009).

40 Macaulay LE and Morris JR, Influence of cluster exposure and winemaking processes on monoterpenes and wine olfactory evaluation of Golden Muscat. Am J Enol Vitic 44:198-204 (1993).

41 Skinkis PA, Bruce PB and Ellen MB, Effects of sunlight exposure on berry and wine monoterpenes and sensory characteristics of Traminette. Am J Enol Vitic 61:147-156 (2010).

42 Guth $\mathrm{H}$, Identification of character impact odorants of different white wine varieties. J Agric Food Chem 45:3027-3032 (1997)

43 Boutou S and Chatonet $\mathrm{P}$, Rapid headspace solid-phase microextractions/gas chromatographic/mass spectrometric assay for the quantitative determination of some of the main odorants causing off-flavours in wine. J Chomatogr A 1141:1 -9 (2007).

44 Morales-Valle $H$, Silva LC, Paterson RRM, Oliveira JM, Venâncio A and Lima N, Microextraction and gas chromatography/mass 
spectrometry for improved analysis of geosmin and other fungal 'off' volatiles in grape juice. J Microbiol Meth 83:48-52 (2010).

45 La Guerche S, Dauphin B, Pons M, Blancard D and Darriet P, Characterization of some mushroom and earthy off-odors microbially induced by the development of rot on grapes. J Agric Food Chem 54:9193-9200 (2006).

46 López R, Ortín N, Pérez-Trujillo JP, Cacho JF and Ferreira V, Impact odorants of different young white from the Canary Islands. J Agric Food Chem 541:3419-3425 (2003).

47 Vilanova M, Genisheva Z, Masa A and Oliveira JM, Correlation between volatile composition and sensory properties in Spanish Albariño wine. Microchem J 95:240-246 (2010).
48 Duarte WF, Dias DR, Oliveira JM, Vilanova M, Teixeira JA, Almeida de Silva JB, et al, Raspberry (Rubus idaeus L) wine: yeast selection, sensory evaluation and instrumental analysis of volatile and other compounds. Food Res Int 43:2303-2314 (2011).

49 Cullereä L, Escudero A, Cacho J and Ferreira V, Gas chromatography-olfactometry and chemical quantitative study of the aroma of six premium quality Spanish aged red wines. J Agric Food Chem 52:1653-1660 (2004). 